\title{
Iron-Mediated Synthesis of Pyrroles from Cyclopropanes
}

Gategory

Synthesis of

Heterocycles

Key words

pyrroles

cyclopropanes

iron catalysis
Significance: The synthesis of highly substituted pyrroles $\mathbf{3}$ from cyclopropanes $\mathbf{1}$ and amines $\mathbf{2}$ via an iron-mediated sequential ring opening-cyclization-dehydrogenation reaction is reported. The conditions were optimized using different solvents, reaction times, and iron catalysts. The scope was studied and cyclopropanes 1 bearing methyl and aryl substituents at $R^{1}$ were tested with the latter giving better yields. EWG- and EDG-substituted aryl amines as well as $\mathrm{R}^{2}=\mathrm{OEt}$ were well tolerated. Also, a methyl group in the cyclopropane $\left(R^{4}=M e\right)$ was suitable, furnishing 1,2,3,5-substituted pyrrole $\mathbf{3}$ in good yield. A series of aromatic and aliphatic amines were screened as well: aliphatic amines furnished pyrroles $\mathbf{3}$ in low yields, while aromatic amines gave better results, although the yields decrease according to the position of the phenyl substituent. A reaction mechanism involving a radical process was suggested based on radical trapping experiments.
Comment: Cyclopropane derivatives can be used as precursors to synthesize a variety of useful heterocyclic motifs (C. A. Carson, M. A. Kerr Chem. Soc. Rev. 2009, 38, 3051; J. R. Green, V. Snieckus Synlett 2014, 25, 2258). The present work reports an efficient synthesis of tri- and tetrasubstituted pyrroles in moderate to good yields from readily available cyclopropanes and amines. The reaction shows a broad substrate scope; both EWG and EDG in $\mathbf{1}$ and $\mathbf{2}$ affording pyrroles $\mathbf{3}$ in comparable yields. While anilines with different patterns of substitution furnished $\mathbf{3}$ in good yields, a large excess of amine was required when benzylamines were used. The readily available cyclopropanes can be easily prepared in high yields by the reaction of a dicarbonyl compound with 1,2dibromoethane (Z. Zhang et al. Angew. Chem. Int. Ed. 2007, 46, 1726). 